\title{
Student Perceptions of an Intelligent Tutoring System: A Technology Acceptance Model Perspective
}

\author{
Abdulkadir Karacı \\ Faculty of Engineering and \\ Architecture, Kastamonu \\ University, Turkey
}

\author{
Zeynep Piri \\ Faculty of Education, \\ Kastamonu University, \\ Turkey
}

\author{
Halil İbrahim Akyüz \\ Faculty of Education, \\ Kastamonu University, \\ Turkey
}

\author{
Göksal Bilgici \\ Faculty of Education, \\ Kastamonu University, \\ Turkey
}

\begin{abstract}
The aim of this study is to understand how students accept an Intelligent Tutoring System (ITS) in terms of the Technology Acceptance Model. For this study, a web-based intelligent tutoring system was used by 38 university students for four weeks. Fifteen randomly selected students participated in two semi-structured focus group interviews which were transcribed and coded. Results showed that $64.12 \%$, of the students perceived the system to be useful, $14.50 \%$ perceived ease of use, and $21.37 \%$, reported an intention to use the instruction system. Among the most frequently reported features of usefulness of the ITS were the repeatability of course materials, effective and permanent learning, the flexibility in time and place of learning, and increased learning performance. While not many students found the system 'fun,' they still frequently reported the intention to use it. Student remarks on the perceived ease of use were less common than those on its perceived usefulness and intention to use. However, the lack of complaints about system usability could mean that they found it sufficient to mention that it was easy to learn and use.
\end{abstract}

\section{Keywords}

Intelligent Tutoring Systems, Student Perceptions, Technology Acceptance Model, Perceived Usefulness.

\section{INTRODUCTION}

Intelligent tutoring systems (ITSs) are computer-based instruction systems that employ methods of artificial intelligence to present students with opportunities for selfdirected and individualized learning by giving intelligent help and guidance. The increasing popularity of ITSs means that computer-based instruction, combined with artificial intelligence and the design of web-based ITSs, have become prominent research areas [1]. The need for time and placeindependent learning has advanced ITSs as an important teaching platform that allows students to learn at their own pace and receive adaptive feedback on their progress.

Typically, an ITS contains three components: a domain model, a student model, and a teaching model. The domain model involves the contents of topics, exam questions, and the relationships among the instruction topics and questions. By monitoring the student, the student model stores information about their learning history, specifically the topics, login and logout times, duration of learning on the system, their answers to the questions, and test scores. The teaching model employs the information stored in the student model to provide them

TAM also focuses on behavioral ITU the system and considers this as a predictor of the system's success [7]. Saade [8] used TAM to examine how his web-based educational information system EISEL was accepted by users. One of his conclusions was that while PU had a significant influence on with intelligent help and guidance. The features and degrees of intelligence can vary extensively from one ITS to another. These systems are generally domain independent, which means the teaching model can be reused in different domains [2].

Adoption of new learning systems is not a straightforward process. This also holds true for ITSs. Jensen and Wilson [3] investigated the reasons for the low level of ITS adoption among American schools. They also revealed the perceptions of teachers and school administrators and their effects on adopting such technologies. In that vein, while suggesting an enhanced TAM for web-based learning environments, Gong et al. [4] emphasized the importance of a user-centered and proactive design approach to learning systems to increase students' perceptions of the system's usefulness and ease of use as well as teachers' willingness to adopt the technology. E-learning systems show their actual potential for providing effective learning only after they are introduced to and used by real users. These interactions shape user perceptions about system use and acceptance over time, which are important for assisting in the development of the system [5].

The ITS implemented in this study is a web-based computer instruction system that employs illustrations and videos along with text. It determines students' knowledge levels via a pretest. The learning content is logically divided into units, topics, and pages. If students can reach the predetermined score for a particular page, they are eligible to skip that page. While the teacher sets a maximum time limit to work on each page, the minimum time limit is set automatically by the system. The login time, time spent on each page, success rate on the exercises, and answers can be monitored by the teacher as well as by the user. The student model is updated after every finished exercise or movement between units.

\subsection{Technology Acceptance Model}

Research in many different technologies and subjects has shown the TAM to be a reliable system for predicting user behavior [6]. It employs the concepts of Perceived Usefulness (PU) and Perceived Ease of Use (PEOU) to determine users' understanding and acceptance of any information system. While PU explains the extent to which users believe using the learning system will improve their performance, PEOU refers to how effortless they perceive system use to be [5]. PU was found to have a significant influence on users' Intention to Use (ITU) the system. Additionally, it should be noted that computer self-efficacy has a strong direct effect on both PEOU and ITU [4] ITU, PEOU did not. Thus, students may not be influenced by the ease of using an educational tool but still intend to use it because of its usefulness, which will make them perform better. However, if the tool is difficult to use, it may be perceived as a barrier to learning and diminish performance. 
Al-Azawei et al. [9] explored the factors that affect technology acceptance and perceived satisfaction in a blended e-learning environment. Moreover, they emphasized the effectiveness of evaluating students' learning individually and according to their learning styles and gender differences, which ITSs allow. The results showed that $31.25 \%$ of the students reported believing that e-learning was an effective solution that could potentially improve teaching and learning in higher education settings, and $18.75 \%$ of the students believed that e-learning could serve as an alternative to make instruction more appealing.

Edmunds et al. [10] used TAM to explore students' ICTrelated experiences. This allowed them to conduct their investigation in not only school but also in work, social, and leisure contexts. Their findings indicate that students' attitudes toward technology are primarily determined by usefulness and ease of use.

Haddaji et al. [11] developed a web-based system to help instructors choose the most appropriate combination of personalization parameters for a particular course. This system was evaluated using TAM. Their results showed that instructors emphasized that the system has a high level of usefulness and ease of use and that they intend to use it in the future.

The literature review showed that a number of studies have examined computer-based learning environments such as elearning environments, blended learning environments, and web-based learning environments which employed TAM [9, 11, 12]. However, no study has yet explored an ITS using TAM to our knowledge. Therefore, our study can fill a crucial gap in the literature by providing suggestions for improving future ITSs.

The aim of this study is to explore how students accept this system in terms of the code schema developed by Yildiz [13] based on the TAM literature. This code schema will enable us to focus on certain aspects of technology acceptance process and elicit feedback from users in a real-life learning context. With the help of this feedback we aim to come up with design suggestions for the development of ITSs that more effectively meet students' needs. Moreover, these will bring out characteristics of ITS which benefit student learning. Section 3 describes the methodology of this study. Section 4 explains how TAM was used to frame the users' reactions to the ITS. Finally, the findings will be presented and discussed using the excerpts from focus group interviews.

\section{METHODOLOGY}

The ITS implemented in this study was intended for online teaching of a standardized information technologies module. 38 Kastamonu University students from a number of departments selected the online course option over taking oncampus lectures. Students used the web-based ITS for four weeks of information technologies instruction. Choosing the off-campus option for the module, students logged on to the system to study any time and any place they wanted. This system allowed them to engage with a variety of learning content from informative texts to practice videos, solve problems at the end of the topics and receive intelligent feedback about their progress and guidance about which topic to proceed. The learning system can be accessed at http://79.123.169.199:8080/index.aspx .

After four weeks, the students who used the Web-based ITS system took the same exam as the on-campus students. Following the exam, 15 of these students volunteered to participate in two groups of focus group interviews. The interviews were recorded using video cameras (1-h durations for each group). The researchers asked about students' perceptions of the usefulness of the system, the convenience and difficulties they experienced using the system, and their ITU the system again.

The methodology of the study is illustrated at Figure 1.

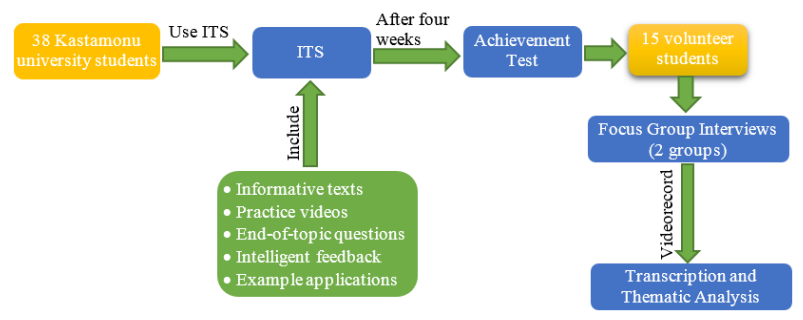

Figure 1: The methodology of the study

For the analysis process, the transcribed transcriptions were coded by three authors based on the TAM code schema developed by Yildiz [13] (see Table 1).

Table 1. The TAM code list (Yildiz, 2011)

\begin{tabular}{|c|c|c|c|}
\hline \multicolumn{2}{|c|}{ Perceived Usefulness (PU) } & Perceived Ease of Use (PEoU) & $\begin{array}{l}\text { Behavioral Intention to Use } \\
\text { (BI) }\end{array}$ \\
\hline (Code 1) & Other perceived usefulness & \multirow{2}{*}{$\begin{array}{l}\text { (Code 6) The Ease of Learning to } \\
\text { Use the System }\end{array}$} & \multirow{2}{*}{$\begin{array}{l}\text { (Code 9) Intention } \\
\text { to Use the System }\end{array}$} \\
\hline (Code 1.1) & Time and Place Flexibility & & \\
\hline$($ Code 1.2) & Equal Opportunity & \multirow{2}{*}{$\begin{array}{l}\text { (Code 7) The Ease of } \\
\text { Using the System }\end{array}$} & \multirow{2}{*}{$\begin{array}{l}\text { (Code 10) Thinking } \\
\text { that The System is Fun }\end{array}$} \\
\hline (Code 1.3) & $\begin{array}{l}\text { Interaction with diverse } \\
\text { cultures }\end{array}$ & & \\
\hline$($ Code 1.4) & Immediate feedback & \multirow{2}{*}{$\begin{array}{c}\text { (Code 8) The Ease of Acquiring } \\
\text { the System Using Skills }\end{array}$} & \multirow{2}{*}{$\begin{array}{l}\text { (Code 11) Learning About } \\
\text { the Developments in the Area }\end{array}$} \\
\hline (Code 1.5) & Multimedia Usage & & \\
\hline (Code 1.6) & Increase in Motivation & & \multirow{2}{*}{$\begin{array}{l}\text { (Code 12) Recommending } \\
\text { the System to Colleagues }\end{array}$} \\
\hline (Code 1.7) & Active participation & & \\
\hline$($ Code 1.8$)$ & Supporting learning & & \multirow{2}{*}{$\begin{array}{l}\text { (Code 13) Thinking that the } \\
\text { Usage of the System will Increase }\end{array}$} \\
\hline (Code 1.9) & Economy & & \\
\hline$($ Code 1.10) & Repeatability & & (Code 14) Thinking that It \\
\hline
\end{tabular}




\begin{tabular}{|c|c|}
\hline \multirow{2}{*}{\multicolumn{2}{|c|}{\begin{tabular}{c|c} 
(Code 1.11) & Lifelong learning \\
(Code 2) Increase in Learning Performance \\
\end{tabular}}} \\
\hline & \\
\hline (Code 3) Efficient Learning Environment & \\
\hline (Code 4) Effective Time Management & \\
\hline (Code 5) Effective Learning Environment & \\
\hline
\end{tabular}

\section{FINDINGS AND DISCUSSION}

An analysis of the answers of students who took the Webbased ITS option of the information technologies course showed that $64.12 \%$ of the students perceived it to be useful, $14.50 \%$ considered it easy to use, and $21.37 \%$ reported an ITU the instruction system again. Eleven out of fifteen students frequently mentioned the usefulness of the ITS (Table 2).

Table 2. The frequency and percentages of TAM codes

\begin{tabular}{|c|l|l|l|l|l|l|}
\hline \multirow{2}{*}{ Participants } & \multicolumn{2}{|c|}{$\begin{array}{c}\text { Perceived } \\
\text { Usefulness } \\
\text { (PU) }\end{array}$} & \multicolumn{2}{c|}{$\begin{array}{c}\text { Perceived } \\
\text { Ease of Use } \\
\text { (PEOU) }\end{array}$} & \multicolumn{2}{c|}{$\begin{array}{c}\text { Behavioral } \\
\text { Intention to } \\
\text { Use (BI) }\end{array}$} \\
\cline { 2 - 7 } & $\mathbf{f}$ & \multicolumn{1}{|c|}{ ( } & f & \multicolumn{1}{c|}{ f } & \% \\
\hline P1 & 8 & 88,88 & - & - & 1 & 11,11 \\
\hline P2 & 3 & 60 & 1 & 20 & 1 & 20 \\
\hline P3 & 9 & 81,81 & 1 & 9,09 & 1 & 9,09 \\
\hline P4 & 3 & 50 & 1 & 16,66 & 2 & 33,33 \\
\hline P5 & 11 & 50 & 3 & 13,63 & 8 & 36,36 \\
\hline P6 & 4 & 66,66 & 1 & 16,66 & 1 & 16,66 \\
\hline P7 & 4 & 57,14 & 2 & 28,57 & 1 & 14,28 \\
\hline P8 & 7 & 77,77 & 1 & 11,11 & 1 & 11,11 \\
\hline P9 & 1 & 33,33 & 1 & 33,33 & 1 & 33,33 \\
\hline P10 & 7 & 77,77 & 1 & 11,11 & 1 & 11,11 \\
\hline P11 & 10 & 66,66 & 3 & 20 & 2 & 13,33 \\
\hline P12 & 6 & 66,66 & 2 & 22,22 & 1 & 11,11 \\
\hline P13 & 3 & 42,85 & 1 & 14,28 & 3 & 42,85 \\
\hline P14 & 3 & 60 & 1 & 20 & 1 & 20 \\
\hline P15 & 5 & 62,5 & - & - & 3 & 37,5 \\
\hline Total & 84 & 64,12 & 19 & 14,50 & 28 & 21,37 \\
\hline & & & & & \\
\hline
\end{tabular}

A detailed analysis of the codes shows that flexibility in time and place, repeatability, and creating an effective learning environment were the most strongly underlined themes in the PU category. These are followed by the codes increasing learning performance and providing an efficient learning environment. In PEOU category, the most emphasized code was the ease of using the system followed by learning to use the system. Among the codes in the behavioral ITU, ITU the system and belief in the prospective increase in the use of such systems were the most frequently mentioned. In the following discussion, the findings will be discussed in terms of the themes of PU, PEOU, and behavioral ITU.

\subsection{Perceived Usefulness (PU)}

University students older than 22 are becoming common and have different family and work commitments than their younger counterparts. As a form of distance education, ITS can also offer equal opportunity for such students by addressing their differing needs. For instance, a common learning challenge for the participants was feeling distracted in a 4-h lecture at a set time. One example was Participant 5, a mother:
'I wanted to be at home when taking this class (code 1.1). I logged on to the system when the kids were sleeping. It directly started from where I left off before. Exercises take a shorter time than in class, but still I learn better by myself (code 2), because the classes are so crowded. You cannot feel as motivated (code 1.6) to learn there. You have to pay attention to both what the teacher says and the exercises at the same time.'

Participant 1 said the following about the usefulness of the ITS:

'When in the classroom, if I asked for help from my lecturer about how to apply my knowledge, that meant I somehow had a gap in my learning. But in this course, I was always redirected to the unlearned topic. And that way, I was pretty much ready when it came to the exercises (code 5). Of course there was the advantage of time and place. I could log in anytime I want, and I could decide how long I would be studying. Not two straight hours like in class. I get easily distracted in class. I could log in and study when I couldn't sleep (code 1.1). So, I don't miss the important basic topics. I couldn't have learned as much in class as I did with this course (code 2).'

Participant 8 explained how his attitude toward learning changed for better with the course format:

I was more relaxed, since I did not have to be somewhere at a set time (code $1.1 \& 4$ ) and learn something in a limited time. You set up your own rules. I think learning is more effective (code 5) if I am relaxed. It was one-to-one, directly addressing me. The content, videos, and exercises (code 1.5) were all self-explanatory. It made a difficult subject easy for me to understand (code 3).'

Participant 14 elaborated on the relaxing side of the ITS:

'I logged on to the system two days before the exam for review. I could recall most of it. I had not forgotten many things that I had to review right before the exam. This made my review time shorter (Code $3 \&$ Code 4), and I was relaxed.'

Like many other participants, Participant 10 cited the flexibility of the system in allowing studying in different times and places, along with other features of the ITS that he perceived as contributing to his success:

'The system enabled us to compensate for several things. You could not make it to class that day? It's gone. But for ITS, there is no settled time (code 1.1.). You can't understand something? You could repeat things over and over (code 1.10). I was more successful this way, while I was bad at the first-term class (code 2). I think this is because I was motivated to continue studying (code 1.6) when I saw the expression 'You have definitely learned this topic' on screen.'

A similar sentiment was expressed by Participant 13:

'I got ambitious when I read the message "It's quite likely that you have not learned this topic" on screen and tried to get it better next time (code 1.6).' 
Participant 15 emphasized the repetition that the system allows:

'It enabled complete learning because I made sure I learned every topic by repeating it. Consolidation makes better learning. It was a great advantage in terms of time (Code 4). I am not a diligent student, but I learned better (code 2) in a third of the time I would have spent in class.'

Participant 11 perceived the importance of feedback and how the ITS could support learning:

'Without feedback (Code 1.4) I could not have known why I got it wrong and to which page I should turn to get it right. It's very sensible of the system to make me repeat my "missing" pages before the exam (Code 1.8). It was way better than going to class, because you cannot unlock the next pages without first learning the current page. It showed the degree of my learning and sometimes "forced" me to repeat a page. The biggest advantage is that you can return to a page from three weeks ago (Code 1.10).'

He, like many others, also cited the freedom that ITS gives to students to choose the length of their learning sessions compared to the seemingly long periods in on-campus classes:

'Distraction is a big problem for me. In class, I would normally listen and learn for the first 20 minutes but then get lost. The system is more comfortable, since I can use it for shorter but more frequent periods. I remember I was slightly afraid of this module at first, but I feel I was more successful at the end (Code 2).'

The ability of the ITS to understand their level of learning astonished some of the participants. Some of them had their own theories about how it could do this:

'I love the fact that I could take notes, and I got tested often in the system (code 1.7). It could even understand what we knew and what we did not know. It could even understand your level of understanding. I think it's something to do with the time you spent on the page.'

Similarly, Participant 2 appreciated the guidance that the ITS provided:

'It even showed us what we have not learned and what we should study next. I liked the immediate feedback. (Code 1.4) In class, I would be lectured and told what I should do. Then I had to try and do all things together. It was not as effective. The course made it possible for me to go one step at a time (Code 5): Learn and apply it immediately.'

Participant 6 suggested that using the same system for other application-based courses would be beneficial, since it would enable them to participate actively:

'Our first-aid lessons lack one-to-one application of knowledge, yet that's so important. It would be much more useful if we used this kind of intelligent system with visual exercises that tell us what we are missing (Code 1.5).'

Participant 13 further elaborated on the multimedia usage and how it resembled a classroom to him:

'The style of the system, the text, the narrative in the videos (Code 1.5) created a classroom atmosphere, but in a more relaxed mood.'

Participant 12 evaluated the effectiveness of the system by comparing it to the on-campus version of the same course that her friends had taken:
'It improved our skills in mathematical operations. I compared myself to friends who had taken the on-campus version. I tried to remind them of some bits of knowledge, but they found it difficult, some had already forgotten it completely (Code 5). I think this was the first time I felt this confident about a computer-related course.'

Among the codes of PU, interaction with diverse cultures (Code 1.3) and economy (1.9) were never mentioned by the participants. Although these features were not implicitly addressed in the design of the ITS, the reason economy was not a factor may be because on-campus education is free at the university, so students might have overlooked the fact that the ITS was also offered free.

\subsection{Perceived Ease of Use (PEOU)}

The codes of PEOU were less frequent than the codes of PU. The participants referred to PEOU briefly when speaking about other things. Participant 4 argued that she could have used this system easily when she was in high school. Participant 11 seconded this sentiment:

'A secondary school student can easily use this system (Code 7). I became quickly familiarized with it (Code 6). Anybody who uses a computer can do it as well. I've had an assumption since primary school that I cannot learn if I am not taught by the teacher. Now I see that if I am guided by feedback and supported by different materials (Code 8), I can learn by myself too. When I graduate, I don't want to be left with the textbook. This system is very good because it will be easily accessible for years. (Code 1.11)'

During four weeks of the course, students did not contact the authors about usability problems. While this could mean that they had no issues using the system, they were asked to explain further. Participant 3 expressed how the option to 'switch' to the on-campus lecture if he needed to reassured him:

'One of the reasons why I preferred to take the module with this system is that if I had difficulty using the system or learning with the system, I was permitted to go to class as well. But I never needed this (Code 6 \& Code 7).'

Participant 9 said the following:

'There was the Help, which I did not recognize for weeks. I don't think I needed it (Code 8). It was like prefaces of books, generally left unread.'

Similarly, Participant 7 found the ITS sufficient for her learning purposes. However, she had a different learning experience with the ITS in terms of time spent. Unlike other participants, who said that ITS made them learn faster, she purposely spent more time with the system to achieve deeper learning:

'I think I spent more time, but I prepared my own detailed notes. I read my friend's notes from class too and realized that the ITS had extra information, especially practical information (Code 3). So it did not harm me to take longer on the ITS. I was thinking about asking the teacher if I had questions, but it never came to that (Code 6).'

Overall, all students concurred with the sentiments of Participant 6 by nodding with approval:

'It is easy to use (Code 7). A computer-literate person can use it easily (Code 7). Everything is easy to find with the left frame to choose the instruction topic to review from it (Code 8). I would definitely recommend it to my other classmates.' 


\subsection{Behavioral ITU}

While the participants often expressed their intentions to continue using ITS for learning in other courses, they took a critical approach that does not allow technological determinism. A teacher candidate, Participant 4, cited some limits of the system for her own use:

'If other courses were offered next term, I would choose to take them (Code 14). But for example, there are some modules in which we make presentations. This helps us to speak better and act comfortably in class, so this system would not be as beneficial.'

Participant 5, the mother, thought using ITS was a good idea and cautiously suggested other possible ITS-based courses to be offered:

'I said I have kids, so I chose to use this system, but I would still take it (Code 9) if I didn't. It can be used for the standard courses that every program has in its curriculum if the contents change slightly for different programs. But for particular courses specific to programs, we generally need a human lecturer for guidance.

Moreover, she perceived a change of her attitude about distance education:

'The system changed my attitude toward distant education for the better. If another course is offered using this, I would surely take it! (Code 14) In fact, I asked if there would be any, but for now there aren't (code 11). I also recommended this to friends.' (Code 12)

Participant 3 also suggested other subjects to be taught with ITS:

'I don't think this system will work for every subject, especially if it requires student-teacher contact. But I think it would be useful for courses that involve different perspectives. These would be presented to us according to our preferences. I would have liked it if the Art and Aesthetics course was offered like this course (Code 14). Then, I would be able to see the artworks, sometimes in 3-D, and however many times I want, along with the information about them. I could examine all of the works separately. That would be more permanent learning. It would save me the confusion that happens just before exams.' (Code $9 \& 14)$

Participant 4 did not have previous online experience, and the ITS also helped him form his ideas about online education:

'I had thought that distant learning meant I would log onto the system where topics are presented in a traditional way, or I wouldn't log in at all, and you (teachers) cannot monitor us. I would take an exam at the end, and then you would check my score. But this course changed my thoughts about distant learning.' (Code 14)

\section{CONCLUSION}

This study explored undergraduate students' acceptance of an ITS using the TAM. Because of their differing time commitments, students in this study used the ITS to accommodate their needs. Moreover, some of them realized that the capabilities and flexibility of the ITS changed their attitudes toward learning and especially toward online learning. It is important to note that they were critical of the system, which allowed them to make suggestions about future offerings of the ITS course.

Data collected from focus group interviews revealed that the most emphasized aspects of the PU of the ITS were the flexibility to use it in different times and places, the ability to repeat material, and an effective learning environment. While students found the system easy to learn and use, they also reported that they intended to use the system and believed that such systems would gain popularity in the future. These results show that this ITS improved learning performance by creating an effective learning environment. Therefore, familiarizing teacher candidates and teachers with such systems can help support their adaptation to technology.

\subsection{Limitation}

The focus group interviews essentially collected the selfreported perceptions of the users. It should be noted that the results were derived from these indirect reports of use. Additionally, knowing about the participants' levels of computer self-efficacy would have been useful, since highlevel users would intuitively perceive the ITS to be easy to use.

\subsection{Suggestions}

While this ITS was developed for undergraduate education, future studies can explore how secondary school and high school students react to ITS. Additionally, ITSs designed for other subjects can be evaluated with TAM.

\section{REFERENCES}

[1] Huang, J. and Chen, Z. (2016), The research and design of web-based intelligent tutoring system, International Journal of Multimedia and Ubiquitous Engineering, 11(6), pp.337-348.

[2] Freedman, R., Ali, S. S., \& McRoy, S. (2000), Links: what is an intelligent tutoring system? Intelligence, 11(3), 15-16.

[3] Jensen, A. \& Wilson, D.M. (2010), The Impact of Teacher/Administrator Perceptions of Risk on the Adoption and Use of Intelligent Tutoring Systems in U.S. Schools. In J. Sanchez \& K. Zhang (Eds.), Proceedings of E-Learn 2010--World Conference on ELearning in Corporate, Government, Healthcare, and Higher Education (pp. 1841-1849).

[4] Gong, M., Xu, Y., \& Yu, Y. (2004), An enhanced technology acceptance model for web-based learning. Journal of Information Systems Education, 15(4), 365.

[5] Masrom, M. (2007), Technology acceptance model and e-learning, Technology, 21(24), 81.

[6] Lee, Y., Kozar, K. A., \& Larsen, K. R. (2003), The technology acceptance model: Past, present, and future, Communications of the Association for information systems, 12(1).

[7] Legris, P., Ingham, J., \& Collerette, P. (2003). Why do people use information technology? A critical review of the technology acceptance model. Information \& management, 40(3), 191-204.

[8] Saadé, R. G. (2003), Web-based educational information system for enhanced learning, EISEL: Student assessment. Journal of Information Technology Education, 2, 267-277.

[9] Al-Azawei, A., Parslow, P., Lundqvist, K. (2017), Investigating the effect of learning styles in a blended elearning system: An extension of the technology acceptance model (TAM), Australasian Journal of Educational Technology, 33(2). 
[10] Edmunds, R., Thorpe, M. and Conole, G. (2012), Student attitudes towards and use of ICT in course study, work and social activity: A technology acceptance model approach, British Journal of Educational Technology, 43: 71-84.

[11] Haddaji R., Essalmi F., Hamzaoui S., Tlili A. (2017), Toward the selection of the appropriate e-learning personalization strategy. In: Popescu E. et al. (eds) Innovations in Smart Learning. Lecture Notes in Educational Technology. Springer, Singapore.
[12] Evans, N. D., \& Le Roux, J. (2015), Modelling the acceptance and use of electronic learning at the University of Zululand, South African Journal of Libraries and Information Science, 81(2), 26-38.

[13] Yildiz, E. (2011), Web tabanlı senkron derslerin öğretmen adaylarının uzaktan eğitime karşı tutumları ve senkron teknolojileri kabulleri üzerine etkisi.

(Unpublished masters thesis) Balıkesir Üniversitesi Fen Bilimleri Enstitüsü, Balıkesir. 